\title{
Correlation of elevated mast cell and micro-vessel densities with lymph node metastasis in oral squamous cell carcinoma
}

\author{
Kalpana Nakandala ${ }^{1}$, Anura Suraweera ${ }^{2}$, Primali Jayasooriya ${ }^{2}$ \\ 'Department of Medical Laboratory Science, Faculty of Allied Health Science, University of Peradeniya, Peradeniya 20400, Sri Lanka. \\ ${ }^{2}$ Department of Oral Pathology, Faculty of Dental Sciences, University of Peradeniya, Peradeniya 20400, Sri Lanka.
}

Correspondence to: Prof. Primali Jayasooriya, Department of Oral Pathology, Faculty of Dental Sciences, University of Peradeniya, Peradeniya 20400, Sri Lanka. E-mail: primalij@yahoo.com

\begin{abstract}
How to cite this article: Nakandala K, Suraweera A, Jayasooriya P. Correlation of elevated mast cell and micro-vessel densities with lymph node metastasis in oral squamous cell carcinoma. Stomatological Dis Sci2018;2:4. http://dx.doi.org/10.20517/2573-0002.2017.17
\end{abstract}

Received: 20 Oct 2017 First Decision: 11 Feb 2018 Revised: 15 Mar 2018 Accepted: 2 Apr 2018 Published: 23 Apr 2018

Science Editor: Mônica Ghislaine Oliveira Alves Copy Editor: Jun-Yao Li Prduction Editor: Huan-Liang Wu

\begin{abstract}
Aim: Oral squamous cell carcinoma (OSCC) is a major health problem in Sri Lanka. Tumor-node-metastasis (TNM) staging system is the tool which is used to determine the extent of surgery in patients with OSCC. However, some patients may receive over-treatment with TNM staging. Mast cells can be found in the oral mucosa. Mast cells secrete different angiogenic factors stimulating angiogenesis which is important in metastasis of tumors. This study aimed to evaluate the mast cell density (MCD) and micro-vessel density (MVD) in OSCC and correlate it with nodal metastasis.
\end{abstract}

Methods: The study sample consisted of one hundred OSCC specimens from patients who were treated surgically with both local excision of the tumor and neck dissections. The sections with OSCC present in achieved biopsies were evaluated for MCD and MVD using toluidine blue stain and a vascular marker (polyclonal rabbit anti-human von Willebrand factor) respectively. The correlation between MCD and MVD with nodal metastasis was statistically evaluated using point bi-serial correlation test.

Results: There was a statistically significant correlation between MCD and nodal metastasis $(P=0.003)$ and MVD and nodal metastasis $(P \leqslant 0.000$ ). These results indicate that MCD and MVD are significantly higher in OSCC with nodal metastasis. In addition, there was a weak positive correlation with MCD and MVD $(r=0.244$ ) (Linear regression and Pearson correlation test). Higher statistically significant MCDs were observed in the buccal mucosal OSCC compared to OSCC of the tongue $(n=100, P=0.023)$. There were no statistically significant differences when MCD and MVD were correlated with age, gender or degree of differentiation of the tumor.

Conclusion: Significantly, high MCD and MVD at the advancing front of the OSCC might be used to identify tumors that present with nodal metastasis. With further studies, this finding could be applied to determine the extent of surgery required for patients with OSCC.

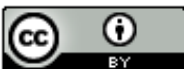

(C) The Author(s) 2018. Open Access This article is licensed under a Creative Commons Attribution 4.0 International License (https://creativecommons.org/licenses/by/4.0/), which permits unrestricted use, sharing, adaptation, distribution and reproduction in any medium or format, for any purpose, even commercially, as long as you give appropriate credit to the original author(s) and the source, provide a link to the Creative Commons license, and indicate if changes were made.

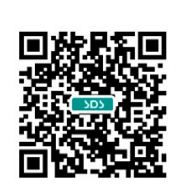


Keywords: Oral squamous cell carcinoma, mast cell density, micro-vessel density, angiogenesis, nodal metastasis

\section{INTRODUCTION}

Oral squamous cell carcinoma (OSCC) is the sixth most common malignant tumor in the world $\mathrm{d}^{[1]}$. It is an invasive epithelial malignancy with varying degrees of squamous differentiation induced predominantly by tobacco usage ${ }^{[1]}$. In Sri Lanka, habits of chewing betel quid which contains tobacco, areca nut, lime paste and condiments wrapped in betel leaf by both males and females; smoking and alcohol abuse by males, tend to increase the incidence of oral cancers ${ }^{[2]}$.

Management of OSCC starts with a comprehensive history and physical examination. Clinical and radiological diagnosis is used to assess the extent of the disease, which is commonly expressed as the tumornode-metastasis (TNM) staging system. According to the TNM staging system, stage I and II indicate a relatively small primary tumor without the involvement of lymph nodes. Stage III and IV demonstrate large primary tumors with or without invasion into underlying structures and spread to regional lymph nodes ${ }^{[2]}$.

Surgical resection of the primary lesion, neck dissection, and postoperative radiation are used for treating patients with OSCC $^{[3]}$. The five-year survival rate of OSCC remains low due to uncontrolled or recurrent tumors and lack of suitable markers for early detection ${ }^{[4]}$. Prognostic factors of OSCC include TNM stage, the thickness/depth of invasion of the primary tumor, invasive front grading, host response and perineural invasion. Out of all known prognostic factors, the most significant prognostic factor is the presence of tumor metastases in lymph nodes which can be used in prediction of poor patient survival ${ }^{[5,6]}$.

Mast cells (MCs) are granular cells present in connective tissues. They are considered as complex and multifunctional cells which play a major role in immunopathology and tumor angiogenesis ${ }^{[7]}$. MCs are a good source of proteases (tryptase and chymase) which directly degrade the extracellular matrix through their proteolytic activity and indirectly stimulate angiogenesis and facilitate invasion and metastasis through extracellular matrix remodeling. Hence MCs have an impact both on the development of the primary tumor and tumor progression and metastasis in OSCC ${ }^{[8]}$. The role of the MCs in OSCC has been investigated in many studies. The total number of MCs have been found to be statistically significantly increased in OSCC when compared to normal controls ${ }^{[7,9]}$. According to experimental models, there is a gradual increase in MC counts in the transition from dysplasia to OSCC $^{[8]}$.

Angiogenesis is a process that plays a role in the pathogenesis of malignant tumors ${ }^{[10]}$. A previous study has shown that neo-vascularization enhances the progression and metastasis in tumors of the oral cavity ${ }^{[11]}$. Thus, it can be postulated that MCs secrete angiogenic factors which promote progression and metastasis in OSCC ${ }^{[12,13]}$. A positive relationship between micro-vessel density (MVD) and a worse prognosis in head and neck tumors had been demonstrated ${ }^{[14]}$. According to the literature, in summary, MCs have been shown to increase the $\mathrm{MVD}^{[12-14]}$ which in turn will play a role in producing lymph nodal metastasis.

Therefore, the present study was designed to evaluate whether mast cell density (MCD) and MVD in the primary OSCCs are reliable markers to identify patients who present with metastasis in the regional lymph nodes. If the study is successful, it will reduce the morbidity associated with extensive surgery, as it will allow identification of patients with nodal metastasis accurately prior to surgery. It will also help to determine the extent of surgery required for patients, which in turn may result in improved outcome and survival of OSCC patients. 
The main aim of the study was to evaluate the MCD and MVD in OSCC of the buccal mucosa and tongue.

\section{Specific objectives of the study}

1. To correlate MCD and MVD with the presence \& absence of lymph node metastasis;

2. To evaluate the differences in the MCD and MVD depending on age and gender of the patient and site of occurrence of OSCC;

3. To assess the relationship between MCD and MVD.

\section{METHODS}

Formalin-fixed paraffin-embedded biopsies of 100 patients with OSCC in buccal mucosa and tongue were selected from the archives of the Department of Oral Pathology, Faculty of Dental Sciences for the study. All patients who had undergone both local excisions and neck dissections were selected to include 50 OSCC patients with regional nodal tumor metastasis and 50 OSCC patients without nodal metastasis. All excision biopsies of OSCC were selected starting from the May 2017 till the sample size of 100 was reached. Relevant information such as patient's age, gender, and histopathological diagnosis (well/moderately/poorly differentiated OSCC) were gathered from biopsy request forms, and biopsy reports of the relevant patients and the information were entered in to excel sheets in coded numerals. Then representative specimens of OSCC were selected from the local excisions by reviewing the existing H\&E stained sections. Selected specimens were immunohistochemically assessed using pre-diluted primary antibody (polyclonal rabbit anti-human von Willebrand factor; Dako, Denmark) for the enumeration of MVD and a toluidine blue stain was performed for the enumeration of MCD for two adjacent tissue sections on separate slides according to manufacturers' instructions.

The ethical clearance for the study was obtained from the Faculty of Allied Health Science, University of Peradeniya. As the study is based on OSCC specimens obtained for diagnosis/treatment, patient consent (written) was obtained at the time that the biopsy was taken. Further, biopsies that have been used have been de-identified prior to analysis.

\section{Enumeration of MCD and MVD}

The stained slides were observed under high power $(\times 40)$, and the tumor invasive margins near to advancing front of the tumor were identified [Figure 1]. MCs were identified as magenta colored granulocytes adjacent to the invasive tumor margins [Figure 2A and B]. Cells were counted in 5 high power fields.

MVs were identified as golden brown vessels without muscle layers adjacent to the invasive tumor margin at the advancing front [Figure $2 \mathrm{C}$ ]. These micro-vessels were counted in five high power fields. Other thickwalled blood vessels (existing vessels not produced by the tumor-related factors) in the tissue sections were considered as the internal positive control for the immunostain Von Willebrand factor VIII.

MCD and MVD were calculated using the following formula:

The diameter of the microscope field $(\mathrm{mm})=$ Field number of the eyepiece/Objective magnification; The density of the cells/vessels $\left(\mathrm{mm}^{2}\right)=$ Sum of cells in 5 high power fields/(Diameter of the microscope field $\times 5$ ).

\section{RESULTS}

Table 1 shows the clinical and pathological characteristics of patients presenting with OSCC. Approximately $93 \%$ of the study sample comprised of patients older than 41 years of age. The majority of the patients were males, with a male to female ratio of 2.5:1. When the clinicopathological characteristics 


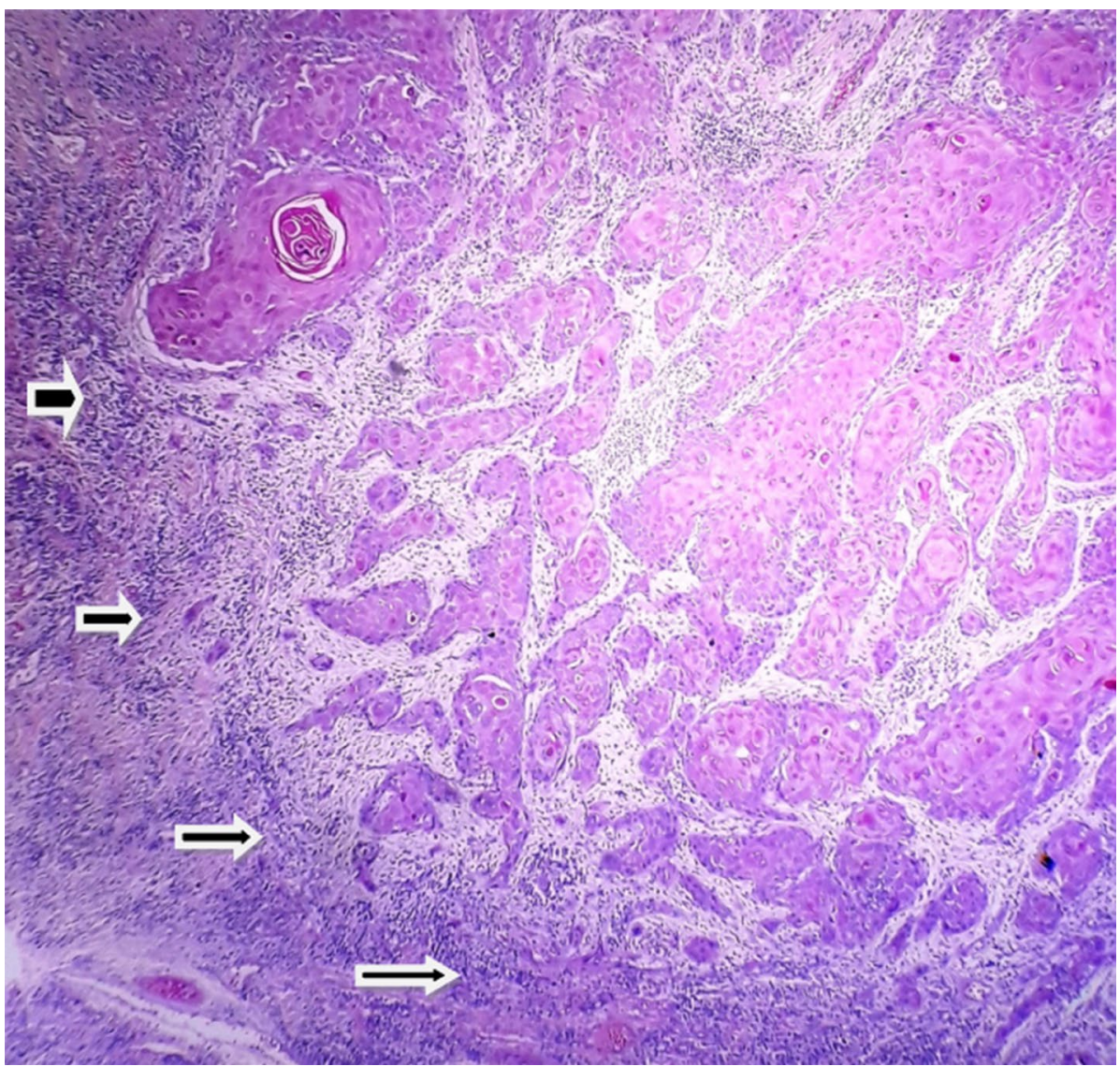

Figure 1. Invasive front of oral squamous cell carcinoma (hematoxylin and eosin stain $\times 4$ ). Note invasive front indicated with arrows

Table 1. Clinical and pathological characteristics of the OSCC patients included in the study sample

\begin{tabular}{ll}
\hline Features & No. of cases $(\boldsymbol{n}=\mathbf{1 0 0})$ \\
\hline Age (years) & $7(7 \%)$ \\
$<40$ & $49(49 \%)$ \\
$41-60$ & $44(44 \%)$ \\
$>61$ & $72(72 \%)$ \\
Gender & $28(28 \%)$ \\
Male & \\
Female & $49(49 \%)$ \\
Site & $51(51 \%)$ \\
Buccal mucosa & $46(46 \%)$ \\
Tongue & $45(45 \%)$ \\
Degree of differentiation & $9(9 \%)$ \\
WDSCC & \\
MDSCC & \\
PDSCC &
\end{tabular}

OSCC: oral squamous cell carcinoma; WDSCC: well differentiated squamous cell carcinoma; MDSCC: moderately differentiated squamous cell carcinoma; PDSCC: poorly differentiated squamous cell carcinoma

of the study sample were compared with patients presenting with and without nodal metastasis, higher number of males and poorly/moderately differentiated OSCCs showed nodal metastasis.

Mean value of the MCD in patients with nodal metastasis was $25.35 \pm 11.95$ per $\mathrm{mm}^{2}$ while patients without metastasis had an MCD of $19.15 \pm 8.38$ per $\mathrm{mm}^{2}$. Mean value of the MVD in patients with nodal metastasis was $32.02 \pm 8.43$ per $\mathrm{mm}^{2}$ and patients without metastasis showed an MVD of $25.43 \pm 9.42 \mathrm{per}^{2} \mathrm{~m}^{2}$ [Figure 3].

A point-biserial analysis was performed to determine the correlation between MCD, MVD and nodal metastasis in OSCC. There was a statistically significant correlation between MCD and nodal metastasis $(n=100, P=0.003)$. That means the patients who developed nodal metastasis had a higher statistically 

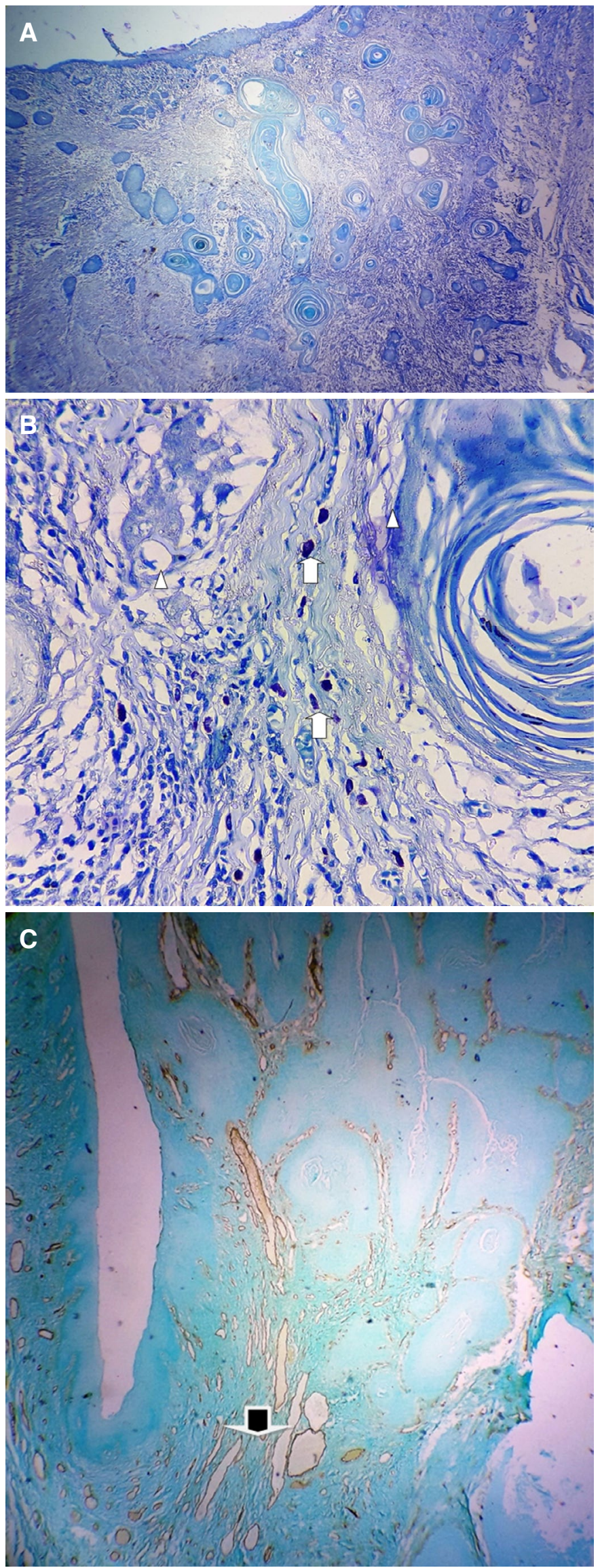

Figure 2. (A) Toluidine blue stain to demonstrate the invasive front (note mast cells are not seen at this magnification); (B) toluidine blue stain to show mast cells $(x 40)$. Arrows indicate the areas with mast cells while triangles show tumour nests; (C) immunohistochemical staining to show micro-vessels ( $x 4)$ (golden brown color vessels x10) 


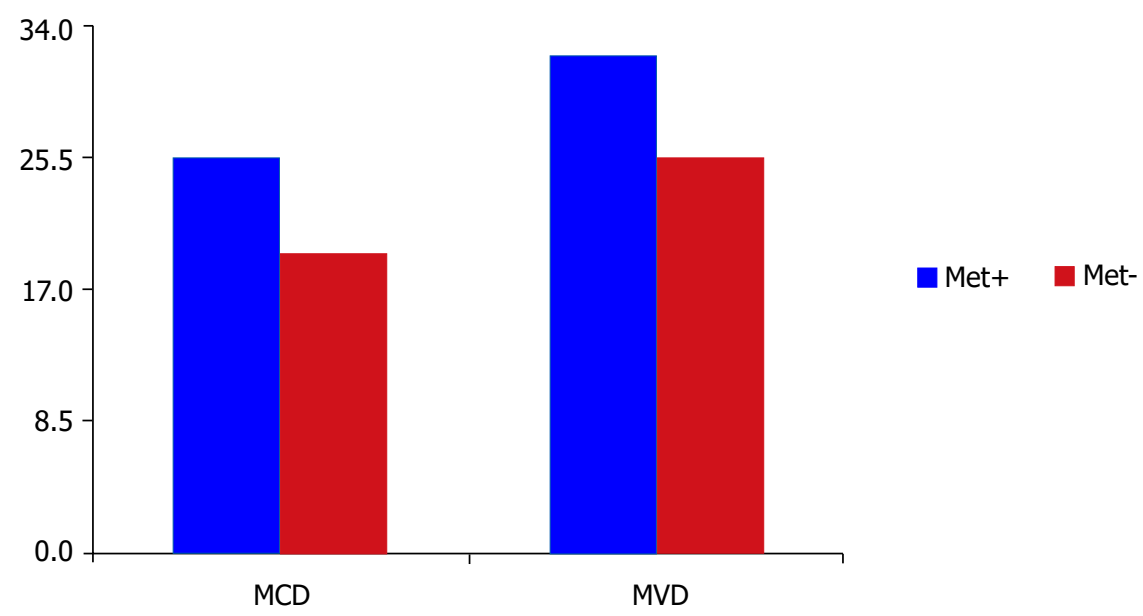

Figure 3. The relationship between elevated MCD and MVD with lymph node metastasis. High mean MCD $(P=0.003)$ and MVD $(P=0.000)$ values for tumors that produce lymph node metastasis compared to tumors without metastasis. MCD: mast cell density; MVD: micro-vessel density

Table 2. Distribution of mean MCD and MVD according to tumor charateristics

\begin{tabular}{|c|c|c|c|c|c|}
\hline \multirow[b]{2}{*}{ Features } & \multicolumn{2}{|c|}{ MCD (cells per $\mathrm{mm}^{2}$ ) } & \multicolumn{2}{|c|}{ MVD (cells per $\mathrm{mm}^{2}$ ) } & \multirow[b]{2}{*}{$\begin{array}{c}\text { Significance } \\
X^{2}(P<0.05)\end{array}$} \\
\hline & $\begin{array}{l}\text { With nodal } \\
\text { metastasis }\end{array}$ & $\begin{array}{l}\text { Without nodal } \\
\text { metastasis }\end{array}$ & $\begin{array}{l}\text { With nodal } \\
\text { metastasis }\end{array}$ & $\begin{array}{l}\text { Without nodal } \\
\text { metastasis }\end{array}$ & \\
\hline \multicolumn{6}{|l|}{ Age (years) } \\
\hline$<40$ & 25.04 & 18.00 & 27.94 & 22.40 & MCD vs. nodal metastasis $(P=0.053)$ \\
\hline $41-60$ & 28.70 & 21.47 & 32.52 & 25.97 & MVD vs. nodal metastasis $(P=0.43)$ \\
\hline $\begin{array}{c}>61 \\
\text { Gender }\end{array}$ & 20.97 & 17.42 & 31.01 & 25.33 & \\
\hline Male & 25.13 & 19.45 & 29.35 & 27.33 & MCD vs. nodal metastasis $(P=0.833)$ \\
\hline Female & 25.42 & 19.00 & 32.86 & 24.50 & MVD vs. nodal metastasis $(P=0.732)$ \\
\hline \multicolumn{6}{|l|}{ Site } \\
\hline Buccal mucosa & 26.60 & 22.42 & 31.41 & 26.91 & MCD vs. nodal metastasis $(P=0.023)$ \\
\hline Tongue & 23.90 & 16.57 & 32.73 & 24.24 & MVD vs. nodal metastasis $(P=0.490)$ \\
\hline \multicolumn{6}{|c|}{ Degree of differentiation } \\
\hline WDSCC & 22.93 & 25.46 & 36.60 & 18.53 & MCD vs. nodal metastasis $(P=0.82)$ \\
\hline MDSCC & 24.34 & 18.12 & 31.20 & 26.60 & MVD vs. nodal metastasis $(P=0.275)$ \\
\hline PDSCC & 28.03 & 19.10 & 31.74 & 25.44 & \\
\hline
\end{tabular}

MCD: mast cell density; MVD: micro-vessel density; WDSCC: well differentiated squamous cell carcinoma; MDSCC: moderately differentiated squamous cell carcinoma; PDSCC: poorly differentiated squamous cell carcinoma

significant MCD compared to patients without nodal metastasis. Similar findings were also observed for MVD and showed a statistically significant correlation between MVD and nodal metastasis $(n=100, P \leq$ 0.000). That means the patients who developed nodal metastasis had higher statistically significant MVD compared to patients without nodal metastasis.

Table 2 shows the MCD and MVD in OSCCs that presented with and without nodal metastasis. A pointbiserial analysis revealed a higher statistically significant MCDs in the OSCC of the buccal mucosal compared to the OSCC of the tongue $(n=100, P=0.023)$. There were no statistically significant differences when MCD and MVD were correlated with age, gender or degree of differentiation of the tumor.

Linear regression analysis and Pearson correlation were performed to evaluate the correlation between MCD and MVD. According to the analysis correlation between MCD and MVD was $r=0.244$. The magnitude, or the strength, of the association between MCD and MVD, is weakly statistically significant 


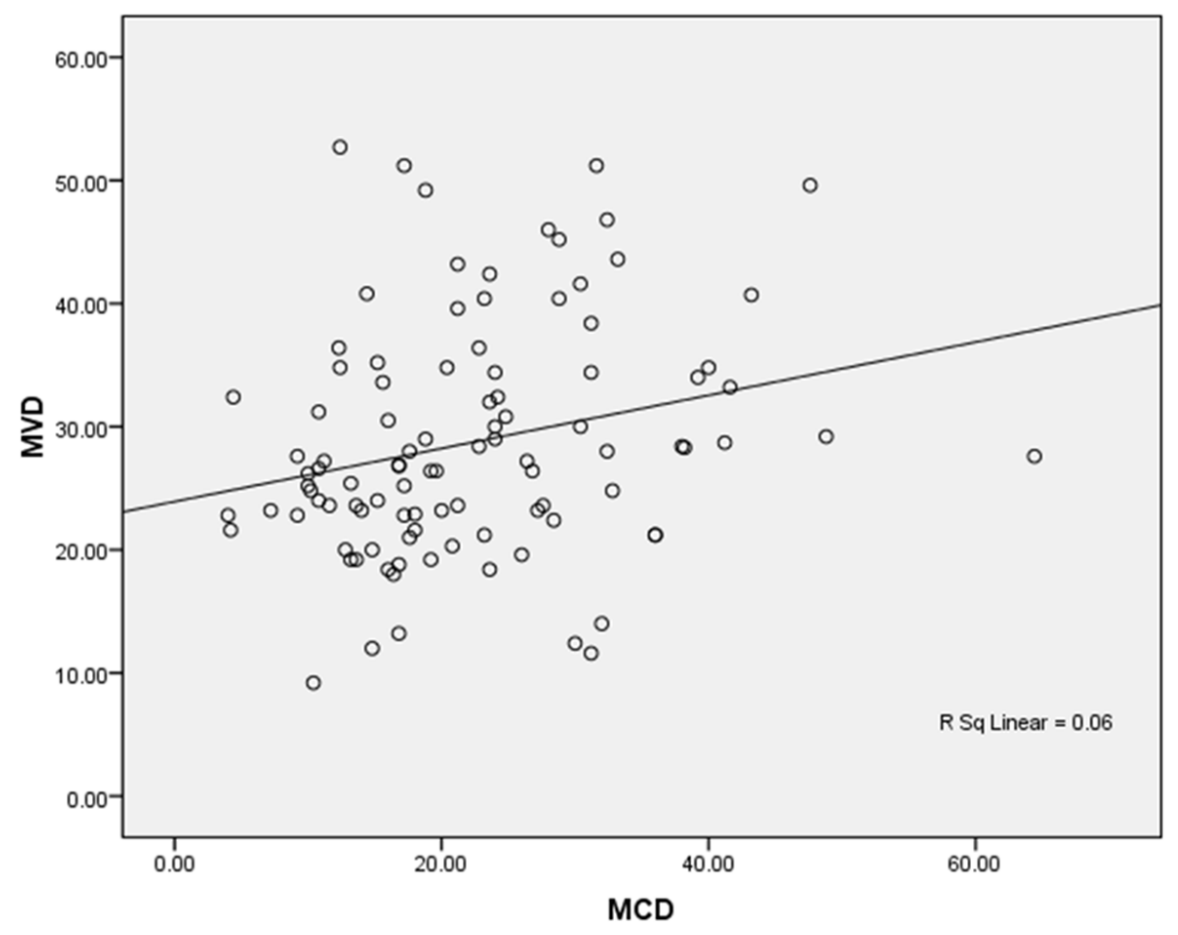

Figure 4. Relationship between MCD and MVD $(r=0.244)$. MCD: mast cell density; MVD: micro-vessel density

[Figure 4]. That means an increase in MCD would give rise to increase in MVD as well. However, the increase in MVD may occur due to factors other than mast cells resulting in the $r$ value obtained for the present study.

\section{DISCUSSION}

Metastasis is defined as a process giving rise to secondary malignant growths at a site distant to the primary tumor. It is a complex and multistep process involving detachment of cells from the primary tumor, local invasion, entry into vasculature, proliferation, and evasion through the lymphatic system or blood vessels ${ }^{[15]}$. Previous studies have shown significant recurrence rates and frequent metastasis to cervical lymph nodes with OSCC ${ }^{[2,16]}$. Surgical removal of the primary tumor with neck dissection to remove affected lymph nodes is generally performed as treatment of $\operatorname{OSCC}^{[3]}$. However, the majority of the clinically positive necks on histopathological evaluation do not show nodal metastasis ${ }^{[2]}$. Therefore it is mandatory to investigate parameters that would predict more accurately the presence of nodal metastasis prior to surgery.

MCs play a major role in the tumor progression. MCs accumulate around the tumor margins and release pro-angiogenic and angiogenic factors which favor tumor progression ${ }^{[17]}$. MCs in tissues can be identified using histochemical stains like toluidine blue, alcian blue and immunohistochemistry using tryptase, heparin, chymase and, carboxypeptidase ${ }^{[8]}$. In the present study, $1 \%$ toluidine blue stain was used for the identification and enumeration of MCs. Anuradha et al. ${ }^{[7]}$ showed significantly increased MCs counts in OSCCs when compared to the normal oral mucosa. The influence of the contribution of MCs to tumor invasion has also been shown in oral cancers ${ }^{[17]}$. However, to the best of our knowledge literature on the contribution of mast cells for nodal metastasis in OSCC does not exist.

In the present study, a significant correlation between MCD and nodal metastasis was found in OSCC. Further, in this study, there was no statistically significant correlation between MCD with age, gender, and 
degree of tumor differentiation. In contrast, Kalra et al. ${ }^{[18]}$ showed that inter-comparison within the degree of differentiation with MCs count was decreased from well differentiated to poorly differentiated OSCC. The contribution of different etiological factors in the formation of OSCC in the two studies may have contributed to this difference.

In the present study, there was a statistically significant correlation between MCD with the site of the tumor. Mean MCD were significantly higher in OSCC of buccal mucosa compared to the tongue. In Sri Lanka, a habit of chewing betel quid which is kept in the buccal mucosa for long time periods may contribute to the increased MCD observed for buccal mucosal OSCC.

Angiogenesis is important in tumor proliferation as well as the metastatic spread of cancer cells which depends on an adequate supply of oxygen and nutrients and the removal of waste products. More than a dozen of different types of proteins have been identified as angiogenic activators. Examples being, vascular endothelial growth factor (VEGF), basic fibroblast growth factor, angiogenin, transforming growth factor- $\alpha$, tumor necrosis factor- $\beta$, platelet-derived endothelial growth factor, granulocyte colony stimulating factor, placental growth factor, interleukin-8, hepatocyte growth factor, and epidermal growth factor ${ }^{[15]}$. New blood vessel formation occurs due to the imbalance between positive and negative factors produced by both the tumor and host cells. Angiogenesis is an unfavorable survival indicator in cancers of the oral cavity ${ }^{[17]}$. A study has shown that angiogenesis as the significant variable of recurrence in patients with OSCC $^{[17]}$. According to the results of the present study higher MVD was found in OSCC patients who presented with nodal metastasis as well.

Micro-vessels in tumors have been evaluated by different vascular markers in several recent studies ${ }^{[19,20]}$. The most commonly used markers are VEGF, CD 31, CD 34 and von Willie brand factor ${ }^{[19]}$. In the present study, MVD was enumerated using immunohistochemistry with von Willie brand factor which is better than other antibodies due to the better highlighting of vessels and its lesser nonspecific staining ${ }^{[20]}$.

Nodal metastasis is a very important contributing factor of prognosis and is more frequently encountered than distant metastasis in OSCC ${ }^{[1,2,7]}$. Sedivy et al. ${ }^{[2]}$ showed a statistically significant correlation between MVD and nodal metastasis in OSCC. In present study as well a statistically significant correlation was found between MVD and nodal metastasis. However, there was no statistically significant association between MVD and clinical variables such as age, gender, site, and degree of differentiation of the tumor. Similar results have been shown by Ascani et al. ${ }^{[13]}$ namely their study also did not show a statistically significant correlation between MVD and age, gender, tumor size and site of the tumor.

MCs can secrete angiogenic factors that enhance the angiogenesis of a tumor ${ }^{[8]}$. A previous study has shown that increased MCD and MVD in OSCC when compared to the normal oral mucosa, however, they could not demonstrate a statistically significant correlation between MCD and MVD in OSCC ${ }^{[18]}$. Another study has demonstrated a relationship between MCs, angiogenesis, and histological progression from normal oral tissues to leukoplakia with different grades of dysplasia up the OSCC, with a significant correlation, observed between MCD and MVD in leukoplakia with different grades of dysplasia and OSCC $^{[17]}$. In this study, there was a positive correlation between MCD and MVD. However, the relationship was weak as many factors other than MCs are capable of stimulating angiogenesis.

In conclusion, this study confirms that MCD and MVD are higher in OSCCs presenting with nodal metastasis than in tumors without nodal metastasis. Therefore, higher MCD and MVD values can be used indicate the presence of nodal metastasis. However, further studies using larger samples are required to determine the cutoff points of MCD and MVC to predict nodal metastasis. At such a time, MCD and MVD can be evaluated in primary OSCC prior to neck dissection and can be used as a tool together with 
TNM staging to determine the extent of surgery which will prevent over-treatment in OSCC patients. It will help to reduce mortality and morbidity of patients with OSCC and to improve their survival rates to some extent.

\section{DECLARATIONS}

\section{Acknowledgments}

Authors gratefully acknowledge the contribution by Dr. Jon Wagner for refining the language of the final manuscript.

\section{Authors' contributions}

Did the immunohistochemical investigations and toluidine blue staining, writing and literature survey:

Nakandala K

Teaching and providing guidance for the staining protocols: Suraweera A

Developed the concept, provided guidance for the writing, critical evaluation of content and manuscript corrections: Jayasooriya P

\section{Data source and availability}

Raw data are available with the principal investigator Jayasooriya P.

\section{Financial and support sponsorship}

None.

\section{Conflict of interest}

The authors hereby declare no conflicts of interest for any product/procedure mentioned.

\section{Patient consent}

Patient consent (written) was obtained at the time that the biopsy was taken.

\section{Ethics approval}

The ethical clearance for the study was obtained from the Faculty of Allied Health Science, University of Peradeniya.

\section{Copyright}

(c) The Author(s) 2018.

\section{REFERENCES}

1. Gale N, Pilch BZ, Sidransky D, Westra WH, Califano J. Epithelial precursor lesions. In: Barnes L, Eveson JW, Reichart P, Sidransky D, editors. World Health Organization Classification of Tumours. Pathology and Genetics of Head and Neck Tumours. Lyon: IARC Press; 2005. p. 177-80.

2. Jayasooriya PR, Pitakotuwage TN, Mendis BR, Lombardi T. Descriptive study of 896 oral squamous cell carcinomas from the only University based Oral Pathology Diagnostic Service in Sri Lanka. BMC Oral Health 2016;16:1.

3. Spencer KR, Ferguson JW, Wiesenfeld D. Current concepts in the management of oral squamous cell carcinoma. Aust Dent J 2002;47:2849; quiz 351.

4. Taghavi N, Yazdi I. Prognostic factors of survival rate in oral squamous cell carcinoma. Arch Iran Med 2015;18:314-9.

5. Ow TJ, Myers JN. Current management of advanced resectable oral cavity squamous cell carcinoma. Clin Exp Otorhinolaryngol 2011;4:110.

6. Natarajan S, Mahajan S, Boaz K, George T. Prediction of lymph node metastases by preoperative nuclear morphometry in oral squamous cell carcinoma: a comparative image analysis study. Indian J Cancer 2010;4:406-11.

7. Anuradha A, Kiran Kumar Naik B, Vijay Srinivas G, Devi RS, Puneet HK. Incidence of mast cells in oral squamous cell carcinoma: a short study. J Oncol 2014;2014:614291.

8. Gaje PN, Amalia Ceausu R, Jitariu A, Stratul SI, Rusu LC, Popovici RA, Raica M. Mast cells: key players in the shadow in oral inflammation 
and in squamous cell carcinoma of the oral cavity. Biomed Res Int 2016;2016:9235080.

9. Elpek G, Gelen T, Aksoy N, Erdogan A, Dertsiz L, Demircan A, Keles N. The prognostic relevance of angiogenesis and mast cells in squamous cell carcinoma of the oesophagous. J Clin Pathol 2001;54:940-4.

10. Tae K, El-Naggar AK, Yoo E, Feng L, Lee JJ, Hong WK, Hittelman WN, Shin DM. Expression of vascular endothelial growth factor and microvessel density in head and neck tumorigenesis. Clin Cancer Res 2000;6:2821-8.

11. Iamaroon A, Pongsiriwet S, Jittidecharaks S, Pattanaporn K, Prapayasatok S, Wanachantararak S. Increase of mast cells and tumour angiogenesis in oral squamous cell carcinoma. J Oral Pathol Med 2003;32:195-12.

12. Gaje P, Bocon V, Cimpean AM, Izvernariu DA, Streian F, Raica M. Simultaneous demonstration of mast cells and blood vessels by the combined method CD 34-alcian blue-safranin in lip tumors. Rom J Morphol Embryol 2007;48:237-41.

13. Ascani G, Balercia P, Messi M, Lupi L, Goteri G, Filosa A, Stramazzotti D, Pieramici T, Rubini C. Angiogenesis in oral squamous cell carcinoma. Acta Otorhinolaryngol Ital 2005;25:13-7.

14. Oliveira-Neto HH, Gleber-Netto FO, de Sousa SF, França CM, Aguiar MC, Silva TA, Batista AC. A comparative study of microvessel density in squamous cell carcinoma of the oral cavity and lip. Oral Surg Oral Med Oral Pathol Oral Radiol 2012;113:391-8.

15. Noguti J, De Moura CF, De Jesus GP, Da Silva VH, Hossaka TA, Oshima CT, Ribeiro DA. Metastasis from oral cancer: an overview. Cancer Genomics Proteomics 2012;9:329-35.

16. Michailidou EZ, Markopoulos AK, Antoniades DZ. Mast cells and angiogenesis in oral malignant and premalignant lesions. Open Dent $J$ 2008;2:126-32.

17. Mohtasham N, Babakoohi S, Salehinejad J, Montaser-Kouhsari L, Shakeri MT, Shojaee S, Sistani NS, Firooz A. Mast cell density and angiogenesis in oral dysplastic epithelium and low- and high-grade oral squamous cell carcinoma. Acta Odontol Scand 2010;68:300-4.

18. Kalra M, Rao N, Nanda K, Rehman F, Girish KL, Tippu S, Arora A. The role of mast cells on angiogenesis in oral squamous cell carcinoma. Med Oral Patol Oral Cir Bucal 2012;17:e190-6.

19. Jahanshani G, Sabaghia M. Comparative immunohistochemical analysis of angiogenesis and mast cell density in oral normal mucosa and squamous cell carcinoma. Dent Res J (Isfahan) 2012;9:8-12.

20. Kabiraj A, Jaiswal R, Singh A, Gupta J, Singh A, Samadi FM. Immunohistochemical evaluation of tumor angiogenesis and the role of mast cells in oral squamous cell carcinoma. Available from: http:/www.cancerjournal.net/preprintarticle.asp?id=163693;type $=0$ [Last accessed on 4 Apr 2018]

21. Sedivy R, Beck-Mannagetta J, Haverkampf C, Battistutti W, Hönigschnabl S. Expression of vascular endothelial growth factor-C correlates with the lymphatic microvessel density and the nodal status in oral squamous cell cancer. J Oral Pathol Med 2003;32:455-60. 